\title{
Intraperitoneal haemorrhage- A call for laparotomy as second intervention
}

\author{
Suniti Rawal, Ashma Rana, Kesang D Bista, Geeta Gurung, Ram K Ghimire' \\ Department of Obstetric and Gynaecology \& Radiology?, \\ Tribhuvan University Teaching Hospital, Kathmandu, Nepal
}

\begin{abstract}
Aim: To study laparotomy as second intervention for hemoperitoneum following primary surgery in obstetric and gynecology.

Method: Eleven years retrospective study going back from Dec 2006 embracing all the cases of re/laparotomy for intraperitoneal bleeding were carried out in TUTH, Nepal.

Results: Of the 24 cases complicated by intraperitoneal hemorrhage for which relaparotomy had been done 12 each were formed by gynaecologic and obstetric cases: 11 were caesareans (CS) and a laparotomy following vaginal birth after caesarean (VBAC). In gynecology the preceding surgeries undertaken were [diagnostic laparoscopy (1), laparotomy (3), hysterectomies 8 (3 being vaginal)] Massive hemoperitoneum occurred in $1 / 4$ cases; extensive hematoma in a third having altogether with associated risks factor in 9(37.5\%).Source of bleeding were disligated/abraded infundibulopelvic vessel (3), cuff bleeding (4), cardinal ligaments (1), uterine cornua (1), uterine angles (6), vagina (1) and placental bed (1) which were duly managed by 5 obstetrics hysterectomy. Laparotomy $>2$ times were repeated 4 : obstetric 2 [(1) for vault bleeding following hysterectomy done for scar rupture after VBAC and other for slippage of ovarian vessel following hysterectomy and internal iliac ligation] and same number in Gynecology 2 [(1) after vaginal hysterectomy first for laceration of infundibulopelvic vessel and then for generalized ooze and hematoma]. Next was following a diagnostic laparoscopy, complicated by unexplainable intraperitoneal bleeding first devised by internal iliac ligation, then finally by hysterectomy that died.

Conclusions: Careful tying of the blood vessel, choosing right technique and appropriate ligature in the first place is as important as proper closure of all the surgical incision/ inflicted cut taking note of the rise in the pulse rate and fall in the blood pressure in overall postoperative cases such that related morbidity and mortality from late diagnosis leading to delayed second surgical intervention can be obviated or minimized.
\end{abstract}

Key Words: Intraperitoneal bleeding, hemoperitoneum, relaparotomy

\section{Introduction}

Hemoperitoneum is one of the dreaded complications following any procedure as simple as culdoscentesis or vaginal delivery to ones embracing vaginal hysterectomy, where laparotomy: an early abdominal second intervention have been advocated. ${ }^{1,2}$ Having the abdomen opened once already "relaparotomy" is a better described terminology incorporated for pack removal, in postoperative hemorrhage following with the primary defect persisting in the uterine wall after caesarean section or following myoma enucleation. ${ }^{3-4}$ In acute postoperative hemorrhages, 42 relaparotomies were done with lethal issues in $16.7 \% .^{5-9}$ Here we will be concentrating on laparotomy as second interventions for hemorrhagic complication arising from gynecological and obstetric surgery aiming to find out our constraints to convene a remedy .

Correspondence

Dr. Suniti Rawal, $M D$

Lecturer, Department of Obstetrics and Gynaecology Tribhuvan University Teaching Hospital, Kathmandu, Nepal

Email: sunudinurawal@yahoo.com 


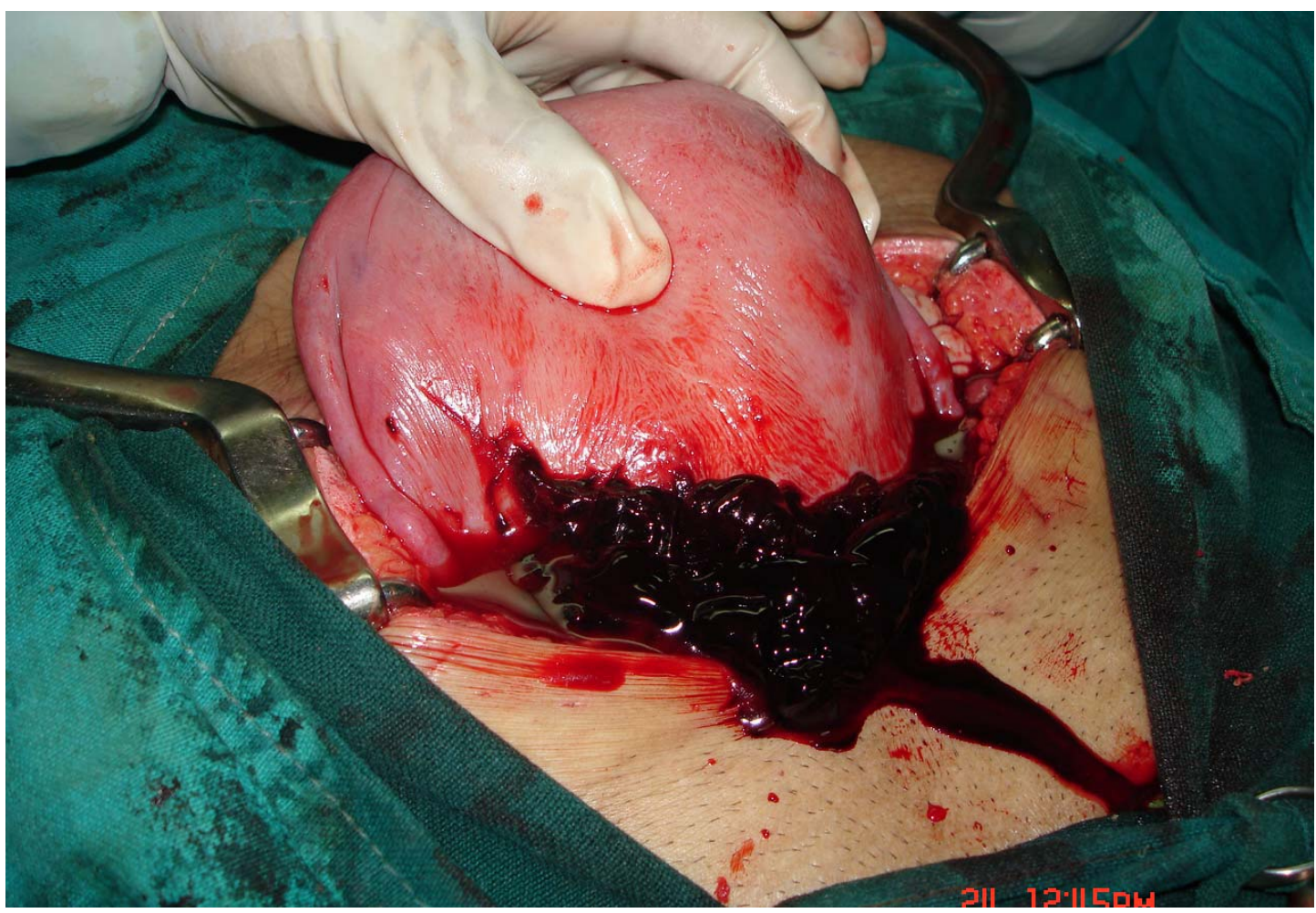

Figure I. Clots over the lower uterine incision closure line

\section{Methodology}

Retrospective analysis of laparotomies and relaparotomies performed for intraperitoneal hemorrhage after vaginal or abdominal procedure in the Department of Obstetrics and Gynaecology, Tribhuvan University Teaching Hospital, for the past 11 years (April 1995-2006) was done. Source: Operation Theater registers and case sheets from medical record section. Information was taken from Faculty member involved in the case managed. Questions asked were whether there has been any relaparotomy for hemorrhagic complication arising from abdominal / vaginal surgical procedures. Has ever a cesarean needed reopening for intraperitoneal bleeding. If yes, when was the complications noted after the primary surgery? Places where the complications were detected, either in Operation Theater itself after the completion of the procedure, outside the operation theatre, in the recovery room or postoperative ward? What had been done as subsequent management for the control of the hemorrhage?

\section{Exclusion criteria}

Those cases that had relaparotomy for sepsis, bleeding in the anterior abdominal wall, rectus sheath haematoma, paralytic ileus and burst abdomen due to infections were excluded.

\section{Results}

Over these years there were 24 [12 Obstetrics ( 1 referred from outside) and 12 Gynecological (2 referred from outside)] cases that needed relaparotomy for the hemorrhagic complications were put together to analyze these cases.

In Obstetric: except for a case of vaginal birth after caesarean section (VBAC) out of ventouse delivery (included because of relaparotomy for intraperitoneal bleeding arising from vault after hysterectomy) rest 11 were CS [8 primary: indications were fetal distress (4), breech in primi (1), eclampsia (1), CPD (1), placenta previa (1) and previous CS (3) of which one was a case of marginal placenta previa. Obstetric hysterectomy (Table1) was done in 5 cases at relaparotomy [preceding indication for 4 CS being (1) with repeat cesarean for placenta previa and all 3 were primary CS; fetal distress(2), cephalopelvic disproportion CPD (1), latter with death on the (operating) table due to severe postpartum haemorrhage (PPH) leading to disseminated intravascular coagulation (DIC). The fifth case, which underwent hysterectomy at laparotomy, was a case of caesarean scar rupture noticed following (ventouse) vaginal delivery after caesarean (VBAC) repeat laparotomy was done for vault bleeding and pack removal with prolonged management for extensive period in the ICU. (Table1, 2) 
Table I. Re- laparotomy for post operative intraperitoneal hemorrhage in obstetric and gynecological surgery

\begin{tabular}{|c|c|c|c|c|c|c|}
\hline \multirow[b]{2}{*}{ Factors } & \multirow[b]{2}{*}{$\begin{array}{c}\mathrm{CS} \\
(\mathrm{n}=11)\end{array}$} & \multicolumn{2}{|c|}{ Laparotomy } & \multirow[b]{2}{*}{$\begin{array}{l}\text { Laparoscopy } \\
\qquad(\mathrm{n}=1)\end{array}$} & \multicolumn{2}{|c|}{ Hysterectomy } \\
\hline & & $\begin{array}{l}\text { Obstetrics } \\
\text { preceded by } \\
\operatorname{VBAC}(\mathrm{n}=1)\end{array}$ & $\begin{array}{c}\text { Gynecology } \\
(n=4)\end{array}$ & & $\begin{array}{l}\text { Abdominal } \\
\qquad(n=5)\end{array}$ & $\begin{array}{l}\text { Vaginal } \\
(\mathrm{n}=3)\end{array}$ \\
\hline Risk factors & 5 & 1 & 1 & - & 2 & - \\
\hline Hemoperitoneum $>1 \mathrm{~L}$ & 2 & 1 & & 1 & 1 & 1 \\
\hline Hematoma & 3 & & 1 & & 1 & 3 \\
\hline $\begin{array}{l}\text { Previos scar rupture / } \\
\text { adhesions }\end{array}$ & 1 & 1 & & & 1 & - \\
\hline Generalized ooze & & & & 1 & & 1 \\
\hline $\begin{array}{l}\text { Disligation of } \\
\text { infundibulopelvic vessel }\end{array}$ & 1 & & & & 1 & 1 \\
\hline Cuff bleeding & & & & & 1 & 3 \\
\hline Cardinal ligaments & & & & & 1 & \\
\hline Uterine Cornua & & & 1 & & & \\
\hline $\begin{array}{l}\text { Uterine angles (6) } \\
\text { Unilateral Bilateral }\end{array}$ & 42 & & & & & \\
\hline Colporrhexis & 1 & & & & & \\
\hline Placental bed & 1 & & & & & \\
\hline
\end{tabular}

Time of relaparotomy in $\mathbf{1 1}$ caesarean sections: Time of relaparotomy varied immediately within 15 minutes in the Operation Theater itself when excessive bleeding had been noticed at the time of vaginal toilet at the end of surgery or up to 48 hours when abdominal distension was noted [within an hour (2); 3-4 (2), 4-8 h (3), $12 \mathrm{~h}(1)$, 12- 24 h (3), 48 hours (1)]

Findings at laparotomy in obstetrics: Significant intraperitoneal hemoperitoneum more than 1-2 L were noted in two cases of which maximum amount was found in a case with slippage of ovarian pedicle after bilateral uterine artery ligation and hysterectomy; following cesarean for fetal distress. The other was a case that died, mentioned already. There were 3 cases with extensive hematoma [one who died, a case of colporrhexis and a case with uterine angle ooze).

Bleeding were from insignificant vessel (1), uterine incision (3) fig 1, over the extended vertical limb of the inverted $\mathrm{T}$ incision, repaired in single layer (1), uterine angle (4) fig 2, colporrhexis (1), placental bed (1) and ovarian pedicle (1). These were treated by evacuation of the hematoma and suturing the vaginal rent (1), securing the angles (4), pedicle (1), reopening the loosely stiched lower uterine segment (3) and resuturing it. Repairing the inverted $\mathrm{T}$ shaped (1), applying multiple stitches in the placental bed (1) and securing the ovarian pedicle (1) at relaparotomy following CS.
Risk factors for hemoperitoneum were 4 cases of previous CS one also having marginal placenta previa. There were 2 cases in primary caesaren section one with placenta previa, dealt by hysterectomy, the other was a case with deeply impacted head (in a case of eclampsia) which was complicated by over extension of vertical limb of inverted $\mathrm{T}$ shaped incision at CS, almost resembling to a classical caesarean. In 2 cases (disligation of ovarian vessel after subtotal hysterectomy or VBAC) laparotomy was needed more than once with cent percent survival

There was a maternal mortality even though the surgery was repeated within 8 hours because of lack of appreciation of blood loss which must have more than estimated at second procedure who succumbed to DIC and death on account of haematoma at bilateral uterine angles, extending to the anterior and posterior parietal wall with haemoperitoneum of $>1$ liter. Associated morbidities in 5 subtotal / total hysterectomies were consumptive coagulopathy (1), gapped wound (1), wound infection (1) and spontaneous resolution of intestinal fistula with.

In gynecological surgery: Laparotomy was performed in 3 cases following vaginal hysterectomy and relaprotomy in 9 abdominal surgeries; 1 after diagnostic laparoscopy, 3 after laparotomy and 5 after hysterectomies (Table 2). 
Table 2. After laparotomy for intraperitoneal hemorrhage in obstetrics.

\begin{tabular}{|c|c|c|c|c|}
\hline \multicolumn{3}{|c|}{ Hysterectomy (5) } & \multicolumn{2}{|c|}{$\begin{array}{l}\text { Laparotomy and uterus } \\
\text { preservation post caesarean }\end{array}$} \\
\hline Indication & $\begin{array}{c}\text { Post cesarean } \\
\text { (4) }\end{array}$ & $\begin{array}{l}\text { Laparotomy } \\
\text { following VBAC (1) }\end{array}$ & $\begin{array}{l}\text { Securing uterine angle } \\
\text { and incisions }\end{array}$ & 5 \\
\hline $\begin{array}{l}\text { Bilateral uterine angle } \\
\text { involvement with } \\
\text { hematoma }\end{array}$ & 1 & & Colporrhexis restored & 1 \\
\hline $\begin{array}{l}\text { Failed } \mathrm{B} / \mathrm{L} \text { uterine artery } \\
\text { ligation followed by } \\
\text { internal iliac ligation }\end{array}$ & 1 & & $\begin{array}{l}\text { Reinforcementof } \\
\text { inverted } \mathrm{T} \text { extension }\end{array}$ & 1 \\
\hline Placental bed bleeding & 1 & & & \\
\hline Re/ Relaparotomy & $\begin{array}{l}\text { Hematoma } \\
\text { from slipped } \\
\text { ovarian vessels }\end{array}$ & Cuff hematoma & & \\
\hline
\end{tabular}

Diagnosis of the intraperitoneal bleeding was made from shock with unrecordable pulse and blood pressure (1), shoulder tip pain (1), trickling of fresh blood per vagina (1), severe pallor after abdominal surgery (3), marked abdominal distension and demonstration of fluid thrill and shifting dullness (5). In vaginal hysterectomy hematuria and oliguria after a normal urinary output for 8 hours (1) and suprapubic mass of $12 \times 12 \mathrm{cms}$ (Fig 1) were primary suspects of intraperitoneal bleeding.

Detection of intraperitoneal bleeding was made as early as 3 hours and as late as 4 days $[<6$ hours (2), 6-12 hours (2), 13-24 hour (2) and $>24$ hours in the rest (6) of the cases]. A case was reopened on the $10^{\text {th }}$ postoperative day because of a retroperitoneal haematoma (fig 2) complicating hysterectomy for molar pregnancy. Early pick up were possible when the blood tricked during vaginal toilet at the end of the operation or collapsed shortly in the post operative recovery room or in postoperative ward. Abdominal ultrasonography (USG) was helpful in almost all the cases as it detected fluid in the Morrison's pouch (Fig 3). A thick silk, which was used to tie the vessels was retrieved in a patient who had undergone surgery for myoma in one of the didelphic uterus, the other uterus was thumb sized with no cervix and vagina.

Intraperitoneal blood collection increased from 500$1700 \mathrm{ml}$ owing to the diagnostic delay influencing on to the interventions that are hold up encompassing larger volumes of blood transfusion in of range 4-10 units. Transfusion also depended the length of time involved where 25 units of blood transfusion was demanded from the time of first laparotomy (done outside) for complication following laparoscopy up to the hysterectomy, which was done in our hospital.

In abdominal surgery (9), site of the bleeding were infundibular pelvic vessels following surgery for myoma (just described above), oozing from the left cardinal ligament that occurred in a case of immature teratodermal tumor in a 9 years old girl. Of the two ectopic cases, bleeding was noted from the contra lateral fallopian tube when it had been unnecessarily fiddled although tubal ligation had been done already or from bleeding from mesosalphinx. There was one each of retroperitoneal hematoma, cuff bleeding, bleeding from the bed of the endometriosis and generalized ooze.

Among 3 vaginal hysterectomies vault hematoma in two approximately measuring $12 \times 12 \mathrm{~cm}$ was caused by an arterial spurt. The third case underwent vaginal hysterectomy in the camp that required reopening twice, once at the camp site due to haemoperitoneum? from tearing of infundibulopelvic ligaments (detected by hypotension and tachycardia) which persisted on account of small ooze's left behind forming hematoma amidst hemoperitoneum.

The risk factors were: malignancy, dense pelvic adhesion due to endometriosis and severe hypertension being a case each, the was diagnosed to have retroperitoneal hematoma on the 10 th postoperative day and was opened with benefit of doubt releasing huge amount of blood mixed ascitic content leaving it undisturbed. Vaginal hematoma was evacuated and tiny bleeders were tied with thin silk. Cornual bleeders were retied again, cuff was re-sutured and ovarian vessel was transfixed with thin silk ties. Operating surgeons took special precaution not to override the ligature one on the top of other which has been found in one of the cases. In all these cases gel foam and abdominal drain was placed.

Hospital stay varied from 10-30 days, partly because of wound infections from soakage, and resuture of the abdominal wound. One of the diagnostic laparoscopy for infertility; required reopening for intraperitoneal 


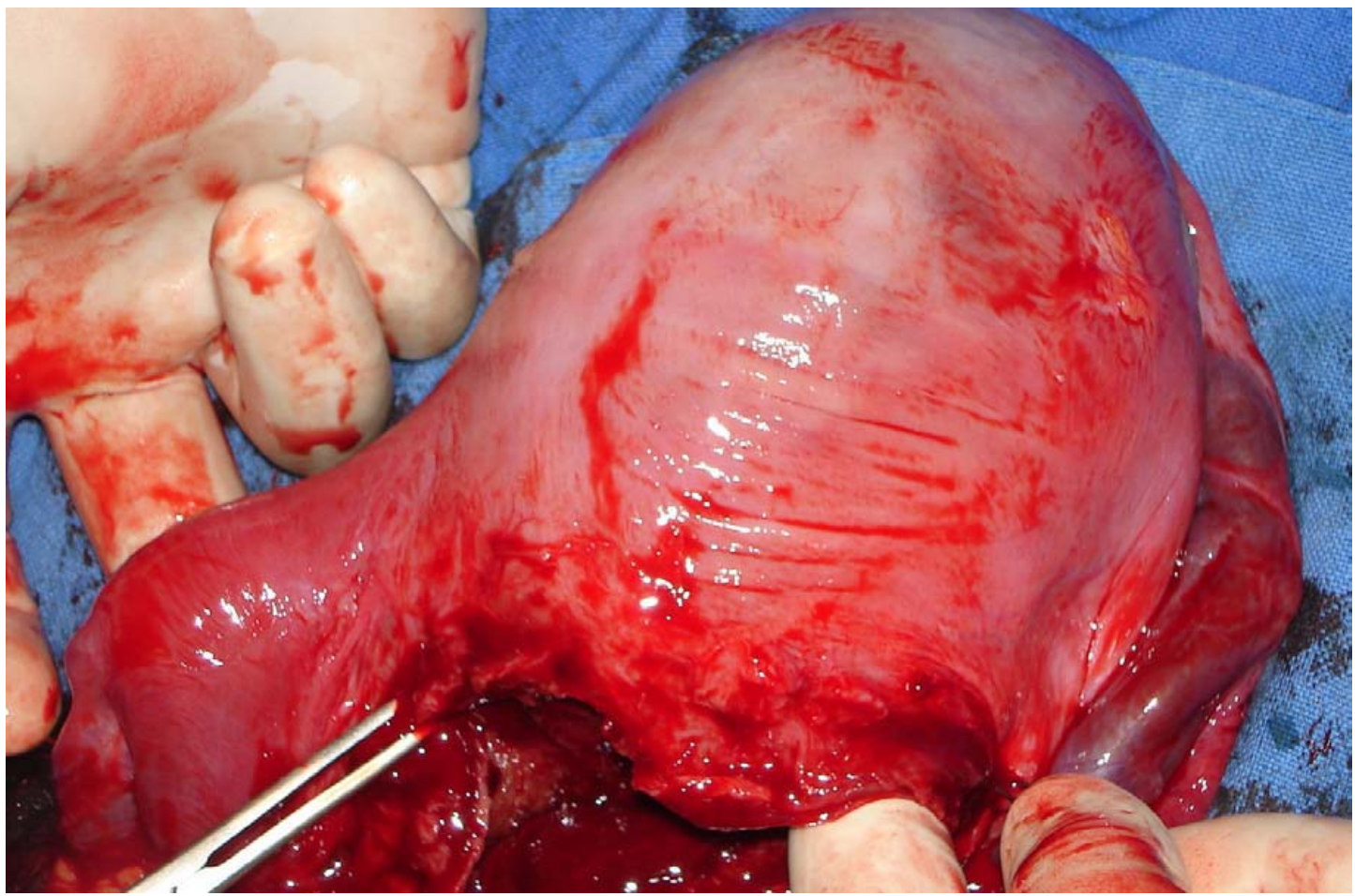

Figure 2. Uterine angle bleeding

hemorrhage twice received more than 25 units of blood transfusion and other blood products but died subsequently from adult respiratory distress syndrome.

\section{Discussion}

Postoperative intraperitoneal haemorrhage in reality is a life threatening situation and has been tactfully combated by relaparotomy both in obstetric and gynecological surgeries as mentioned in two papers written a decade apart. ${ }^{8,9}$ A series of 121 relaparotomies in 16,719 cases of laparotomy have depicted haemorrhage (19\%) as one of most important element amongst the others, such as ileus $(25 \%)$, peritonitis $(32 \%)$, wound rupture and burst abdomen $(22 \%)$, and other causes $(2 \%){ }^{6}$

But this paper only deals with intraperitoneal hemorrhage where 24 relaparotomy were applied as the second intervention. A third (8) of these cases having associated risk factors: two of them were ante partum hemorrhage (APH) formed by major degrees of placental previa and marginal placenta in previously scarred uterus making up 4 previous CS besides totaling to $5 / 12(41 \%)$ in obstetrics surgeries together with $3 / 12$ $(25 \%)$ in gynecology which were bleeding in bed of endometriosis(1), ovarian malignancy with cornueal bleeding(1) and retroperitoneal bleeding in hydatidiform mole on account of acute hypertension(1). Late diagnosis after 24 hours were made in $7(29 \%)$ mainly because of misleading normal vitals or a normalizing vitals after a brief period of circulatory collapse (unrecordable pulse and blood pressure) erroneous to an extent that a temporary improvements presumed after collapse taken for normal well being cost a life in a woman following elective CS for CPD. Even a case of ruptured ectopic tackled by salpingectomy with contralateral tubal ligation when reopened had $1.5 \mathrm{~L}$ of hemoperitoneum who had been deceptively well preserved for 20 hours. This must have been produced from the infusion of crystalloids and colloids coping to replace the intraperitoneal blood loss with fair amount of hydration. Therefore early recognition signs of intraperitoneal hemorrhage are an important aspect since they may not persist for long moving on to fatal ends with temporary illusive sense of recovery. Therefore it is imperative to appreciate even the slightest of the hemodynamic compromise so that early intervention can be introduced. A good example is where the disligated ovarian pedicle was opened within $3 \mathrm{~h}$ of surgery with ultrasound detection of free fluid in Morrison's pouch after a postoperative collapse. Demonstration of shifting dullness with increase abdominal girth due to distension is another way of looking into intraperitoneal hemorrhage which was elicited within 12 hours of surgery (2) or after a slow trickling of vaginal bleeding for significant time (8).Vaginal toileting in operating room itself after caesarean persuading for instantaneous relaparotomy with benefit of doubt has been able to discover bleeders in the uterine angle.

Obstetric hysterectomy is annoying at times when abdominopelvic bleedings becomes intricate to control at relaparotomy with the development of DIC. Here pelvic packing has gained some importance involving 
the use of 10-12 dry pads packed firmly over the alleged bleeding site once the cessation of bleeding is ensured using a pressure pack for 5-10 minutes. ${ }^{3,10}$ This has been applied at caesarean hysterectomy for morbidly adherent anterior placenta previa over a previous CS scar during dire emergency from uncontrollable hemorrhage related coagulopathy. ${ }^{3}$ Removal of the pack has been safely made 36-48 hours later, only one case developing small bowel obstruction on the 5th postoperative day. Failing all measures recombinant factor VIIa (2.4 mg intravenous injection) was found to be effective prior to relaparotomy. ${ }^{11}$ Collagen-fibrin agent (Tacho Comb) has also been found to be a boon for securing perfect hemostasis during laparoscopic approach, judged presently as an attractive alternative to the laparotomy as a second intervention for postoperative bleeding following laparoscopic or vaginal hysterectomy employed in $0.85 \%$ (10/1167). ${ }^{12}$

Relaparotomy for bleeding along with infection have entailed moderate risks somewhere sandwitched between dehiscence and obstruction complying with minimal risk as against highest for highest mortality for anastomotic leak in a study of 55 cases analyzed between 1996- 2000. ${ }^{5}$ There were mortality in two of the 16 cases. ${ }^{6}$ We also had mortalities related to the primary presentation of the patient rather than to the relaparotomy, a reintervention that brought to evidence to technical errors which can be modified being more cautious and vigilant at surgery observing and adhering to general surgical principles as enlisted below such that there will be no further reason to reopen once abdomen closed.

\section{Tips}

* Proper securing of wound edges at CS, looking for extension upward or downward both. The uterine edge bleeding can be secured with figure of 8 sutures. There are suggestions to use square sutures and Heaney sutures, which we have not practiced so far, but we can always remodel ourselves

* Vessel should be ligated thin 00 vicryl (polyglycolic) so that disligation of vessel is prevented. The vascular pedicles are better taken with thin silk suture to avoid disligation.

* Whenever the pedicles are swollen as in one of our case with mullerian abnormality, pedicels must be transfixed.

* Not to overlay one tie over the other, because if the lower one is looser the end result is not hopeful. It is better to take separate suture than to pile one over the other

* Ensure regaining of normal blood pressure (especially with regional anesthetic agents) before closure, this may obviate hematoma from small bleeders which was met in a case with $\mathrm{T}$ shaped extension that was reinforced.

* Whenever the doubt exits to wash the peritoneal cavity by normal saline which opens the bleeding capillaries by washing away the clots, which can be coagulated.

* Have an abdominal drain if there are venous oozers that have been left behind (not for the arterial bleeders) or you have any doubt of bleeding later.

\section{Conclusion}

It is better to acknowledge and anticipate the probabilities of post operative intraperitoneal hemorrhage rather than treat them but at the same time tachycardia and hypotension which are the earliest signs in these cases must be closely monitored and investigated so as to avoid morbidity and mortality related to late relaparotomy.

\section{References}

1. Duff P Sparks J, Hawley C.Extensive. An unusual complication of culdocentesis: intraperitoneal haemorrhage from uterine laceration. J Reprod Med 1983; 28(3): 221-2

2. Banas T, Boryczko M, Durzynska-Urbaniec J. Intraperitoneal hemorrhage due to the rupture of right ovarian artery in the second day of puerperium. Ginekol Pol 2004; 75(9): 729-32.

3. Ghourab S. Abdomino-pelvic packing to control severe haemorrhage following caesarean hysterectomy. J Obstet Gynaecol 1999; 19(2): 155-8

4. Mayer HG, Lirmberger M. Early abdominal second interventions following gynecologic surgery. Zentralbl Gynakol 1975; 97(11): 692-5.

5. Ching SS, Muralikrishnan VP, Whiteley GS. Relaparotomy: a five-year review of indications and outcome. Int J Clin Pract. 2003; 57(4): 333-7.

6. Tera H, Aberg C. Relaparotomy. A ten-year series. Acta Chir Scand. 1975; 141(7): 637-44.

7. Batian NP, Khomchenko MN, Narubanov PG. Relaparotomy in acute hemorrhage after operations on the abdominal organs. Vestn Khir Im I I Grek. 1976; 116(2):68-71

8. Cereseto P1, Fernandez Jm. Gynecological relaparotomy. Dia Med.1962; 34: 771-2.

9. Tamas Z. Emergency relaparotomy after gynecologic and obstetric operations. Orv Hetil. 1972; 113 (33): 1969-71.

10. Holub Z, Feyereisl J, Kabelik L. Successful treatment of severe postpartum bleeding after caesarean section using recombinant activated factor VII. Rittstein T. Ceska Gynekol 2005 Mar; 70(2):144, 146-8.

11. Al-Nuaim LA, Mustafa MS, Abdel Gader AG. Disseminated intravascular coagulation and massive obstetric hemorrhage, management dilemma. Saudi Med J 2002 Jun; 23(6):658-62.

12. Holub Z, Jabor A. Laparoscopic management of bleeding after laparoscopic or vaginal hysterectomy. JSLS 2004; 8(3): 235-8. 